\title{
Experiences of including costs of added life years in health economic evaluations in Sweden
}

Laura Pirhonen ${ }^{1}$, Thomas Davidson ${ }^{2,3}$

University of Gothenburg, School of business, economics \& law, Gothenburg, Sweden

Swedish Council on Health Technology Assessment (SBU), Stockholm, Sweden

3 Center for medical technology assessment (CMT), Linköping University, Linköping, Sweden

\begin{abstract}
It is of importance to include the appropriate costs and outcomes when evaluating a health intervention. Sweden is the only country where the national guidelines of decisions on reimbursement explicitly state that costs of added life years should be accounted for when presenting health economic evaluations. The aim of this article is to, from a theoretical and empirical point of view, critically analyze the Swedish recommendations used by the Dental and Pharmaceutical Benefits Agency (TLV), when it comes to the use of costs of added life years in economic evaluations of health care. The aim is furthermore to analyze the numbers used in Sweden and discuss their impact on the incremental cost-effectiveness ratios of assessed technologies. If following a societal perspective, based on welfare economics, there is strong support for the inclusion of costs of added life years in health economic evaluations. These costs have a large impact on the results. However this fact may be in conflict with ethical concerns of allocation of health care resources, such as favoring the younger part of the population over the older. It is important that the estimates of production and consumption reflect the true societal values, which is not the case with the values used in Sweden.
\end{abstract}

\section{Keywords}

Health economic evaluation; Cost-effectiveness; Survival years

\section{INTRODUCTION}

Health economic evaluations are used in order to inform decision makers in health care and to ensure that limited health care resources are used effectively. It is of great importance to include the appropriate costs and outcomes when evaluating a health intervention or a specific pharmaceutical. Therefore there has been numerous debates on what costs and effects to include and furthermore on what perspective to use $[1,2]$. One much-debated cost is the cost of added life years [3-7], sometimes referred to as survival costs or future unrelated costs among others. Costs of added life years refer to the net consumption (consumption subtracted by production) during the extra years that an individual lives due to a lifesaving intervention or drug. Sweden is the only country where the national guidelines of decisions on reimbursement explicitly state that these costs should be accounted for when presenting health economic evaluations. These guidelines are developed and used by the Dental and Pharmaceutical Benefits Agency (TLV) [8].
Other countries may also have the objective of allocating resources according to a societal perspective but despite this choose to exclude the costs of added life years.

When making decisions on reimbursements TLV in Sweden has three ethical guidelines to follow: the human value principle, the need and solidarity principle, and the cost-effectiveness principle [9]. The first principle says that the health care system should respect the equal value of each individual. The second principle states that the individuals with the largest medical needs should be allocated more resources than other patient groups. The last principle explains that costs due to the use of a drug should be reasonable from the medical, humanitarian, and societal perspective.

The aim of this article is to, from a theoretical and empirical point of view, critically analyze the Swedish recommendations used by TLV, when it comes to the use of costs of added life years in economic evaluations of health care. The aim is furthermore to analyze the numbers used in Sweden and discuss their impact
Corresponding author

Thomas Davidson, CMT Linköping University, Sweden thomas.davidson@liu.se

Disclosure

No funding was provided and no conflicts of interest. 
on the incremental cost-effectiveness ratios of assessed technologies.

The outline of the article is as follows; first the theoretical viewpoints of including or excluding costs of added life years are briefly presented. Thereafter, the present numbers on production subtracted by consumption that are used by TLV in Sweden are presented and explained. Moreover, the impact on the analysis and the decision of reimbursement done by the board at TLV is analyzed by using two pharmaceuticals. In addition, ethical viewpoints are discussed in relation to the inclusion of costs of added life years. All values are presented in US dollars where \$1 = SEK6.94 (06-23-2013).

\section{BACKGROUND}

\section{Cost of added life years}

The background for the debate on whether or not to include costs of added life years is founded on the different theoretical views that exist. If following a straightforward welfarist view, the outcome of an economic evaluations should be utilities and to be able to reach an optimal resource allocation of health the expected utility function of an individual should be maximized, as in the fashion of Meltzer [4]. Generally quality-adjusted life-years (QALYs) are the preferable outcome measure and it is intended to represent individuals' utilities. The inclusion of costs of added life years is then justified by explaining that the utility of future expenditures due to prolonged life of the patient is included in the expected utility function, thereby a factor that the individual takes into account when answering questions related to QALY weights, and therefore the costs of these future expenditures should also be included in an analysis. Garber and Phelps [3] also use an expected utility function but arrive at a different result than Meltzer [4]. Instead of letting survival probabilities of an individual be affected by all medical interventions during a lifetime, Garber and Phelps [3] only let medical expenditure in the first period affect the survival probability in the second period and leaving the third period's survival probability unaffected. This leads to their conclusion of costs of added life years being equivalent to adding a constant in an analysis and thereby them not supporting the inclusion of costs of added life years. If, on the other hand, an extra-welfarist approach is the basis of an analysis the QALYs should be interpreted as, not utilities, but as health or as capabilities, as Sen [10] advocates. If interpreting QALYs as being health or as capabilities the inclu- sion of costs of added life years in an analysis is not straightforward anymore and utilities should be based on, not consumption of goods or services, but something else.

However, even if welfarism is accepted as the general underlying theory, there is an empirical question whether measured QALYs fulfill the criteria of representing individuals' utilities, where studies have shown that this is not the case [11]. Even if there exists a common consensus that QALYs are not simply utilities and should not be interpreted as such, there still are disagreements about what is measured when constructing QALYs and what individuals take into account when answering questionnaires constructed to produce QALY weights. According to Nyman [5] the QALY weights are not constructed so that they include future consumption and production but if they were constructed in this manner the costs of added life years should be included in an analysis. This aspect has been tested in several studies [12-15] but it is nevertheless hard to come to a conclusion. Even though the majority does not appear to consider their economic situation when answering direct methods to elicit QALY-weights, it does not necessarily mean that income does not affect QALY-weights. It is probably the case that most of the respondents assume similar consumption levels as before the change in health state. Lundin and Ramsberg [16] furthermore argue that if QALYs do not measure total utility, where utility from consumption is not included, a large part of consumption expenditures should still be included in the analysis since they are necessary to stay alive and live a normal functioning life. Gandjour [17] also supports the inclusion of costs of added life years due to the fact that the individual receives utility from basic needs such as food and housing when the life of the patient is extended and therefore the costs should be included. Recently van Baal et al. [7] argued strongly for the inclusion of indirect medical costs in economic evaluations .

\section{The recommendation on cost of added life years in Sweden}

Often guidelines state that a societal perspective should be used in economic evaluations, meaning all costs and effects should be included, but often there is no common agreement as to what these costs and effects are. In addition, the terms "related" and "unrelated" are often difficult to disentangle leading to a wide spread of interpretations. Grima et al. [18] highlight this difficulty in their article on dialysis for chronic kidney disease patients. They state that there are large inconsistences in CEAs due to the fact that there is not 
a common understanding to what related and unrelated costs are. The Dental and Pharmaceutical Benefits Agency (TLV) in Sweden chooses a strict societal perspective, and a welfarist approach, by including all costs and effects of an intervention or a drug, also the unrelated non-medical ones. This leads to their guideline about costs of added life years: "If the treatment affects survival, then the costs for increased survival - total consumption less total production during gained life years - should be included» [8]. The inclusion could lead to a decision of reimbursement being accepted or rejected i.e. the costs having a large impact. The inclusion could also be in conflict with the other principles in the ethical platform that TLV should take into consideration when making decisions on reimbursement.

The decision to reimburse pharmaceuticals in Sweden is done by the board at TLV. Their goal is to, through a societal perspective, evaluate all costs and benefits of a certain medical technology, where all costs also means the inclusion of costs of added life years. When these costs are included in an analysis the numbers that should be used according to TLV are calculated in a thesis by Ekman [19], but these numbers have not been presented in a peer-reviewed journal. The numbers are a summary of consumption and production by age from 1997 and are then adjusted by consumer price index (CPI). The whole table can be seen below.

Production is calculated as total labor cost of the employee from the employer's point of view. Health care consists of pharmaceutical expenditures, which are the per capita sales of prescription pharmaceuticals, primary and hospital care are from southern Sweden and these numbers are used as representative numbers for the rest of the country, and dental care numbers are only for the dental care that is not privately provided. The social services costs are collected from the Swedish Association of Local Authorities and Statistics Sweden. Considering the costs of education no detailed information was found in the university education part and therefore the assumption was made that the intensity of study and cost of study was the same for younger and older students. Also, the lack of information led to an assumption that individuals 65 years and older do not participate in the adult school education. Data on public consumption has been collected from Statistics Sweden and data on other private consumption consists of elderly care fees and

\begin{tabular}{|c|c|c|c|c|c|c|c|c|}
\hline \multirow{2}{*}{ Type of consumption } & \multicolumn{8}{|c|}{ Age } \\
\hline & $0-19$ & $20-34$ & $35-49$ & $50-64$ & $65-74$ & $75-84$ & $85+$ & All \\
\hline \multicolumn{9}{|l|}{ Health care } \\
\hline Pharmaceuticals & 78 & 115 & 194 & 349 & 502 & 569 & 479 & 234 \\
\hline Primary and hospital care & 653 & 814 & 1,010 & 1,411 & 2,238 & 3,090 & 3,306 & 1,247 \\
\hline Dental care & 121 & 156 & 186 & 202 & 199 & 194 & 192 & 169 \\
\hline Total & 852 & 1,085 & 1,391 & 1,963 & 2,939 & 3,852 & 3,977 & 1,650 \\
\hline \multicolumn{9}{|l|}{ Social services } \\
\hline Elderly care & 0 & 0 & 0 & 0 & 1,035 & 6,439 & 21,111 & 971 \\
\hline Services to impaired people & 302 & 486 & 486 & 486 & 102 & 102 & 102 & 375 \\
\hline Transportation services & 6 & 6 & 6 & 6 & 38 & 103 & 288 & 21 \\
\hline Total & 308 & 492 & 492 & 492 & 1,176 & 6,645 & 21,501 & 1,367 \\
\hline \multicolumn{9}{|l|}{ Education } \\
\hline Schools and child care & 7,199 & 0 & 0 & 0 & 0 & 0 & 0 & 1,755 \\
\hline Universities & 58 & 1,192 & 224 & 41 & 2 & 0 & 0 & 310 \\
\hline Adult schooling & 18 & 276 & 111 & 15 & 0 & 0 & 0 & 84 \\
\hline Labor market training & 8 & 98 & 70 & 54 & 0 & 0 & 0 & 45 \\
\hline Total & 7,277 & 1,566 & 404 & 110 & 2 & 0 & 0 & 2,195 \\
\hline General public consumption & 2,641 & 2,641 & 2,641 & 2,641 & 2,641 & 2,641 & 2,641 & 2,641 \\
\hline Other private consumption & 8,128 & 12,579 & 11,631 & 15,265 & 13,764 & 10,362 & 7,092 & 11,613 \\
\hline Total consumption & 19,206 & 18,363 & 16,560 & 20,472 & 20,522 & 23,499 & 35,212 & 19,466 \\
\hline Total production & 396 & 21,346 & 32,726 & 29,118 & 1,311 & 149 & 24 & 16,307 \\
\hline Consumption-Production & 18,810 & $-2,982$ & $-16,165$ & $-8,646$ & 19,210 & 23,350 & 35,187 & 3,159 \\
\hline
\end{tabular}

Table I. Costs of added life years in Sweden in 1997 US dollars (USD1 = SEK6.94) (modified from Ekman, 2002 [19]) 
disposable incomes for the elderly, data from the family expenditure survey as well as private health care expenditures. [19]

\section{ANALYSIS OF THE NUMBERS}

The estimates used today when making decisions about reimbursement are dated and may not be truthful estimates of the consumption and production of the population. Due to the fact that these estimates can have an impact on the decisions of reimbursement they need to be critically analyzed. One problem with these estimates is for example the fact that the estimates for production for 65 year olds and older are extremely low and does it really make sense that 65 to 74 year olds only produce $\$ 1,311$ worth every year? There seems to be a lack of formal production for 65 to 74 year olds. Also, one important aspect not considered in the current estimates is the informal production of the whole population, but most importantly the informal production of the population 75 years and older. Furthermore, the estimates are recommended by TLV to be adjusted to today's numbers through CPI, which may or may not be the right method.

The exclusion of informal production from these numbers will most certainly lead to favoring of the younger due to the fact that production in the formal sense will decrease as the individual gets older. The informal production in all is hard to get ahold of but there are some good estimates of the magnitude. In a study presented by Jegermalm and Jeppsson Grassman [20] the aspect of informal production in Sweden is tackled. The group that produces the most in this sector is women 75 years and older who spend 60 hours per month on these activities, and men spend two-thirds of the time on informal production that women do. These activities include transportation, other's household work, looking after others in the society, from the young to the old and spending time with them. There is an increase in the informal production of elderly from 1992 to 2005 and the largest increase is in the care of others, those who are not relatives, where the number has increased from 28 percent to 50 percent in the years observed. [20] The inclusion of informal production in costs of added life years is supported by Meltzer [4]. He wanted to integrate leisure, meaning actual leisure and informal production, in the utility function. This would be done in order to not prioritize the younger population and to show a truthful estimation of the costs.

Moreover, an additional aspect that has changed from the year when the current estimates were calculated is the formal production produced by the elderly. A study from Statistics Sweden shows that 65 and 66 year olds that are in the labor force has increased in Sweden since 2001, from not even five percent to 22 percent in 2009 [21]. One of the reasons for this is a change in the law of employment protection that took place in 2001 and made it possible for employers to work until the month they turn 67. Another aspect when considering changes to the present estimates on production is the fact that there most probably will be an increase in the pension age. This would lead to even larger differences in productivity between reality and the current estimates of productivity and would create an even larger bias. In the current numbers the age group of 65 to 74 year olds has an estimate of productivity of $\$ 1311$ per capita per year and this would clearly be much higher if, and when, the pension age will be increased, and would lead to an even larger need for new estimates for costs of added life years.

\section{RE-ESTIMATION OF PRODUCTION}

It is necessary to update all the estimates used today and below two examples of these updates are presented. As stated above, the productivity of 65 and 66 year olds has increased, as well as for older individuals. In Sweden in 2011, 13.4 percent of 65-74 year olds were employed [21]. Approximating this production and re-estimating the current estimates was done with a recalculation. The new productivity for 65-74 year olds in 2011 SEK was calculated to be $\$ 10.280$, compared to the earlier estimate of $\$ 1311$. Keeping consumption constant and subtracting consumption by production the new cost of added life years for the age group of 65-74 year olds is $\$ 12,362$ in 2011 dollars, reducing the costs by approximately $\$ 10,800$ (47\%) compared to the current numbers.

To calculate the accurate total informal production of the elderly would be an almost impossible task due to the lack of data but estimations can be done to show the importance of informal production. It is of course the case that the younger population also produces informally but the age group 75-84 was chosen to show the importance of adding informal production in the present estimates as well as giving a more truthful estimate of production for elderly who do not produce formally any longer. As stated before, women over 75 years and older spend on average 60 hours a month on informal production and men two-thirds of what women do [20]. It is difficult to estimate the value of this informal production because there is no monetary va- 
lue attached to it and the intensity and quality of the informal production varies between people of different ages and otherwise. Following welfare economics, the cost represent the best alternative use of the resource, which for person in this age group generally is leisure time. The value of leisure is hard to estimate, but it is not zero. Another way to estimate the cost of informal production is by finding its replacement cost, that is, the cost of hiring a professional to do the same job. In the latter case, one has to adjust for effectiveness and quality of a professional. In this example, a value of $50 \%$ of the employer's cost of using a professional health care assistant cost was used, which in Sweden in 2012 was $\$ 12.68$ per hour. This cost was then multiplied with the average hours spent on informal production. To avoid overestimation the age group was not allocated any additional production apart from the existing numbers. After calculations the yearly average informal production of 75 to 84 year olds was found to be $\$ 12,731$ in 2011 dollars. Replacing the current numbers for production of this age group and keeping consumption constant the new costs of added life years is $\$ 15,632$, instead of $\$ 28,183$ (Table II).

Another example illustrating how consumption can change from year to year shows the importance of updated numbers. In order to account for the fact that when years go by the prices differ TLV uses CPI to adjust the estimates from 1997 to today's numbers. But this methodology does not necessarily represent the rightful increase of the estimates. The per capita cost of pharmaceuticals, according to the present estimates, was in 1997 on average \$234. By adjusting \$234 with the CPI between 1997 and 2012 the cost for pharmaceuticals should be $\$ 285$ per capita in 2012. Studying statistics from 2012 [22] shows that the costs of pharmaceuticals per capita on average was \$382 in 2012 equaling a difference of $\$ 97$ between the real number for 2012 and the CPI adjusted number for 2012, an increase with 34 percent. This example shows that the present numbers are underestimating the cost of pharmaceuticals per capita and this could be the case for the other estimates as well.

\section{IMPACT ON THE EVALUATION}

Two recent economic evaluations of pharmaceutical drugs are used as examples to show the impact of including costs of added life years in economic evaluations. These two drugs are dabigatran and zytiga. In neither case the impact of including costs of added life years is presented in the decision made by TLV.

\section{Dabigatran}

Dabigatran is an oral direct thrombin inhibitor and the effect of the drug is predictable and does not need to be monitored but does not have any antidote. Dabigatran is an anticoagulant drug which means that is prevents the blood from clotting. The drug is used to prevent stroke and thrombosis for adult patients with atrial fibrillation.

To study whether dabigatran is a cost-effective drug a health economic evaluation was done [23] which was assessed by TLV. Here, dabigatran was compared to warfarin, in the aspect of the medical effects and costs. When putting together all effects and costs (including certain assumptions requested by TLV), the cost per QALY gained was \$77,089 [24]. The pharmaceutical was approved reimbursement.

As the size of the costs of the added life years are not presented, it was necessary to use the same model as TLV used. The model used indicates that 0.12 QALY and 0.09 life years are won when using dabigatran instead of warfarin and also the avoidance of stroke is 0.05 . When calculating the costs of added life years the current numbers [19] were used, updated with CPI to 2011 year values. In total, including costs of added life years increased the cost per QALY gained with $\$ 20,189$, an increase with 35 percent.

After applying the re-estimated costs of added life years (presented in Table II) that include both informal production of 75 to 84 year olds and increased formal production of 65 to 74 year olds, multiplied with the CPI for

\begin{tabular}{lcc|cc}
\hline & \multicolumn{2}{c}{$\mathbf{6 5 - 7 4}$ year olds } & \multicolumn{2}{c}{$\mathbf{7 5 - 8 4}$ year olds } \\
\cline { 2 - 5 } & $\begin{array}{c}\text { CAL current } \\
\text { numbers (USD) }\end{array}$ & $\begin{array}{c}\text { CAL updated formal } \\
\text { production (USD) }\end{array}$ & $\begin{array}{c}\text { CAL current } \\
\text { numbers (USD) }\end{array}$ & $\begin{array}{c}\text { CAL updated informal } \\
\text { production (USD) }\end{array}$ \\
\hline Consumption & 24,770 & 24,770 & 28,363 & 28,363 \\
Production & 1,582 & 12,408 & 180 & 12,731 \\
Cost of added life years & 23,188 & 12,362 & 28,183 & 15,632 \\
\hline
\end{tabular}

Table II. Example of re-estimated values for certain ages. Increased formal production for 65-74 year olds and informal production for 75-84 year olds in 2011 US dollars (USD1 = SEK6.94)

$\mathrm{CAL}=$ cost of added life years 


\begin{tabular}{lccc}
\hline & $\begin{array}{c}\text { Dabigatran, } \\
\text { base case }\end{array}$ & $\begin{array}{c}\text { Dabigatran with } \\
\text { re-estimated } \\
\text { values of CAL }\end{array}$ & Zytiga \\
\hline Cost/QALY without CAL & 56,900 & 56,900 & 141,643 \\
CAL & 20,189 & 7,638 & 25,504 \\
Total cost/QALY & 77,089 & 64,538 & 167,147 \\
\hline
\end{tabular}

Table III. The impact of costs of added life years on the cost per QALY of dabigatran and zytiga in US dollars (USD1 = SEK6.94)

$\mathrm{CAL}=$ Cost of added life years
Agency also has to make decisions according to the law of health and health care where in paragraph two it says that the goal for the health care system is good health and health care on the same terms for the whole population [27]. Also, health care should be given with respect to the equal value of each individual and with respect to every individual's dignity. The individual with the greatest need for health care should be given priority. From these principles and laws it can be concluded that they stand in contrast to each other and following one principle means bending the other. This is true especially when taking into account costs of added life years in cost-effectiveness analyses where younger are prioritized over the elderly. Because the inclusion of costs of added life years does discriminate the elderly it can be viewed from the point of the fair innings principle [28]. The reason why is because the elderly have already had the chance to live their life, had their fair innings, and therefore the younger population should be prioritized. By including an additional cost, the net consumption that is positive for the elderly due to less production on the cost-side in the analysis, maybe a more rightful result will appear according to the fair innings principle. too high $(\$ 167,147)$ [25]. No information about the costs of added life years was included in the decision. Later they presented information about their calculations in order to guide the county councils in Sweden [26], and it was then stated that an indirect cost has been added on these patients during survival and that these costs are production minus consumption, in other words, costs of added life years. These costs were calculated to be $\$ 8934$ and increased the cost per QALY gained by $\$ 25,504$ (an increase with 18 percent). These values cannot be updated with the recalculated numbers from Table II as the model used was not accessible.

\section{COSTS OF ADDED LIFE YEARS AND ETHICS}

There exist ethical complications when including costs of added life years in health economic analyses. The guideline that TLV need to consider when making a foundation for the decision whether to reimburse a drug or not, is called the ethical platform [9]. The ethical platform consists of three principles, which are: the human value principle, the need and solidarity principle and the cost-effectiveness principle. These principles should be prioritized according to the above ordering, where the cost-effectiveness principle is the last principle that should be taken into account. The Dental and Pharmaceutical Benefits

\section{DISCUSSION}

The guidelines that TLV applies in their health economics evaluations came to place in 2003 meaning they have ten years of experience in including costs of added life years in analyses. Even though these costs have been included in analyses for a decade not many were aware of them until the beginning of 2013 when TLV explicitly wrote that survival of patients with prostate cancer increased societal consumption but not production. This was presented in the information about the health economic calculations of zytiga [26], which was not accepted for reimbursement, and it was the start for a public discussion. One reason behind the previous lack of discussions about the inclusion of costs of added life years was that very few understood how the calculations of costs of added life years were computed as well as not understanding the impact of including these costs. There are strong theoretical arguments for the inclusion of costs of added life years but the decision whether to include or exclude these costs should partly be based on the perspective that the society chooses to have when allocating health care resources. If the society chooses to have a societal perspective, as is the case in Sweden and many other countries around the world, all costs and benefits 
should be included in an analysis according to the interpretation of a societal perspective. In spite of this, Sweden is the only country where it is recommended to include costs of added life years in health economic evaluations. The main reason for this, together with other aspects, is probably the ethical consequences that the inclusion would give rise to as well as the difficulty to disentangle related and unrelated costs. This difficulty to disentangle related and unrelated costs is the reason why there is a discussion about whether to include or not include dialysis in the CEA for patients with chronic kidney disease [18]. According to the article the inclusion of the costs of dialysis will lead to the treatment not being cost-effective and leading to a negative decision on reimbursement.

The inclusion of costs of added life years becomes even clearer when having a welfarist background. As Johannesson and Meltzer [29] stated, these costs are real costs and excluding them would lead to a bias. The cost-effectiveness analysis, with the costs of added life years included, would then be an independent analysis of the cost-effectiveness of a drug or an intervention and should be separated from the ethical platform that also need to be considered. Then, after knowing that all the costs are accounted for and seeing how large the cost-effectiveness ratio is, the human value principle and the need and solidarity principle could be applied and thereafter a decision could be made knowing that all the aspects would be taken into account.

If choosing to have a societal perspective and including cost of added life years, the estimates used for these costs should be re-estimated and updated. The present estimates used in Sweden are from one year only, 1997 [19], and the consumption and production has changed since then. Informal production is a factor that is completely missing from the estimates of production, most probably due to the difficulty in giving a value to informal production. An additional aspect that needs attention is the inclusion of variation in the estimates of costs of added life years. There is uncertainty and a wide spread in the production and consumption for 65 year olds where some could work several more years and others are retired and thereby overestimating or underestimating the costs of added life years for individuals. Furthermore, patients surviving a mortal disease rarely represent the average population and neither produce or consume as average. Additionally, in many cost-effectiveness analyses, a simulation model are used which follow the patients for the rest of their life. In these cases it is common to include health care costs related to the certain health states and if the costs of added life years from Table I are added this would lead to double counting of these costs. Another drawback of the current estimates of costs of added life years is the fact that CPI is added to them in order to upgrade the numbers to today's date but consumption of different goods or services could have increased faster or slower than CPI. All these examples above show that the current estimates of costs of added life years need to be updated and re-estimated.

In order to show the impact of the inclusion of costs of added life years on an analysis two cases with two different drugs were presented, dabigatran and zytiga. In both cases the costs of added life years increased the cost per QALY gained substantially (35\% and $18 \%$ ). Using updated numbers of production in the case of dabigatran the incremental cost-effectiveness ratio was approximately $\$ 12,551$ less.

In Sweden, TLV does not have a threshold value for the cost per QALY but some "cut-offs" can be seen from previous decisions as well as by the guidelines from the National Board of Health and Welfare in Sweden (Socialstyrelsen) [30]. In general the threshold seems to be somewhere between SEK 500,000 (\$72,000) and SEK 1000,000 $(\$ 145,000)$, depending on the need of the patient group. For both the presented drugs in this study, the inclusion of costs of added life years led to the drugs passing these levels (dabigatran for the lower and zytiga by the upper). Whether the costs of added life years had any impact on the decision is however not possible to analyze. These two examples show how large of an impact cost of added life years has on the analysis and also implicates that because of this impact it is important that these estimates are truthful and well thought-out.

Several ethical viewpoints are in line with the inclusion as well as the exclusion of costs of added life years. First of all, the principles that TLV need to consider when making decisions about reimbursement stand in contrast to each other. In the law of health and health care it is specifically stated that the goal of the health care system should be good health and health care on the same terms for the whole population [27]. This goal is contradictory to the principle of cost-effectiveness when costs of added life years are included, health care will not be allocated based on the same terms because individuals are divided according to age. The concept of fair innings can be seen as standing in line with the inclusion of these costs and the studies on the general population stand in line with the inclusion as well. 


\section{CONCLUSIONS}

There is strong theoretical support for the inclusion of costs of added life years if a societal perspective is applied, as is the case in Sweden. The examples used in this article, dabigatran and zytiga, have shown that there is a significant impact on the analysis when making decisions on reimbursement when including costs of added life years. Due to the fact that the inclusion of costs of added life years has an impact the estimates used must be as truthful as possible. As seen, after critically analyzing the present estimates of costs of added life years, it is necessary to make improvements to these estimates that are used by TLV. There are different ethical views that support the inclusion of costs of added life years as well as ethical views that do not support the inclusion. However, the inclusion of costs of added life years clearly contradicts the ethical principle of human value that is included in the law of health and health care in Sweden.

\section{REFERENCES}

1. Brouwer WB, Koopmanschap MA. On the economic foundations of CEA. Ladies and gentlemen, take your positions! J Health Econ 2000; 19: 439-59; http://dx.doi.org/10.1016/S0167-6296(99)00038-7

2. Weinstein MC, Manning WG Jr. Theoretical issues in cost-effectiveness analysis. J Health Econ 1997; 16: 121-8; http://dx.doi.org/10.1016/S0167-6296(96)00511-5

3. Garber AM, Phelps CE. Economic foundations of cost-effectiveness analysis. J Health Econ 1997; 16: 1-31; http:// dx.doi.org/10.1016/S0167-6296(96)00506-1

4. Meltzer D. Accounting for future costs in medical cost-effectiveness analysis. J Health Econ 1997; 16: 33-64; http:// dx.doi.org/10.1016/S0167-6296(96)00507-3

5. Nyman JA. Should the consumption of survivors be included as a cost in cost-utility analysis? Health Econ 2004; 13: 417-27; http://dx.doi.org/10.1002/hec.850

6. Rappange DR, van Baal PH, van Exel NJ, et al. Unrelated medical costs in life-years gained: should they be included in economic evaluations of healthcare interventions? Pharmacoeconomics 2008; 26: 815-30; http://dx.doi. org/10.2165/00019053-200826100-00003

7. van Baal P, Meltzer D, Brouwer W. Pharmacoeconomic guidelines should prescribe inclusion of indirect medical costs! A response to Grima et Al. Pharmacoeconomics 2013; 31: 369-73; http://dx.doi.org/10.1007/s40273-0130042-9

8. Swedish Pharmaceutical Benefits Board (Läkemedelsförmånsnämnden). General Guidelines for Economic Evaluations. Stockholm: Pharmaceutical Benefits Board, 2003

9. Ministry of Health and Social Affairs. No easy choices: The difficult priorities of health care. Stockholm: SOU, 1993

10. Sen, A. Commodities and capabilities. Amsterdam: North-Holland, 1985

11. Mehrez A, Gafni A. Quality-adjusted life years, utility theory, and healthy-years equivalents. Med Decis Making 1989; 9: 142-9; http://dx.doi.org/10.1177/0272989X8900900209

12. Davidson T, Levin LA. Do individuals consider expected income when valuing health states? Int J Technol Assess Health Care 2008; 24: 488-94; http://dx.doi.org/10.1017/S0266462308080641

13. Krol M, Sendi P, Brouwer W. Breaking the silence: exploring the potential effects of explicit instructions on incorporating income and leisure in TTO exercises. Value Health 2009; 12: 172-80; http://dx.doi.org/10.1111/j.15244733.2008.00406.x

14. Myers J, McCabe S, Gohmann S. Quality-of-life assessment when there is a loss of income. Med Decis Making 2007; 27: 27-33; http://dx.doi.org/10.1177/0272989X06297100

15. Tilling C, Krol M, Tsuchiya A, et al. In or out? Income losses in health state valuations: a review. Value Health 2010; 13: 298-305; http://dx.doi.org/10.1111/j.1524-4733.2009.00614.x

16. Lundin D, Ramsberg J. On survival consumption costs: a reply to Nyman. Health Econ 2008; 17: 293-7; http:// dx.doi.org/10.1002/hec. 1290

17. Gandjour A. Consumption costs and earnings during added years of life - a reply to Nyman. Health Econ 2006; 15: 315-7; http://dx.doi.org/10.1002/hec.1065

18. Grima DT, Bernard LM, Dunn ES, et al. Cost-effectiveness analysis of therapies for chronic kidney disease patients on dialysis: a case for excluding dialysis costs. Pharmacoeconomics 2012; 30: 981-9; http://dx.doi. 
org/10.2165/11599390-000000000-00000

19. Ekman M. Studies in Health Economics: Modelling and Data Analysis of Costs and Survival. Dissertation for the degree of Doctor of Philosophy at the Stockholm School of Economics. EFI, Stockholm Sweden, 2002

20. Jegermalm M, Jeppsson Grassman E. Patterns of informal help and caregiving in Sweden: A thirteen-year perspective. Soc Pol Admin 2009; 43: 681-701; http://dx.doi.org/10.1111/j.1467-9515.2009.00689.x

21. Statistics Sweden Nr 62, 2012.Available at http://www.scb.se/Pages/Article 332790.aspx (last accessed September 2013)

22. National board of health and welfare. Läkemedel - statistik för år 2012. Available at www.socialstyrelsen.se (last accessed September 2013)

23. Davidson T, Husberg M, Janzon M, et al. Cost-effectiveness of dabigatran compared with warfarin for patients with atrial fibrillation in Sweden. Eur Heart J 2013; 34: 177-83; http://dx.doi.org/10.1093/eurheartj/ehs157

24. Swedish Dental and Pharmaceutical Benefits Board (TLV). Pradaxa. TLV, 2011. Available at http://www.tlv.se/ Upload/Beslut_2011/111130-Pradaxa_dnr1222-2011.pdf (last accessed September 2013)

25. Swedish Dental and Pharmaceutical Benefits Board (TLV). Zytiga. TLV, 2012. Available at http://www.tlv.se/ Upload/Beslut_2012/120530-zytiga.pdf (last accessed September 2013)

26. Swedish Dental and Pharmaceutical Benefits Board (TLV). Hälsoekonomiskt kunskapsunderlag - Zytiga. TLV, 2012. Available at http://www.tlv.se/Upload/Halsoekonomiska_bedomningar/halsoekonomiskt-kunskapsunderlagzytiga.pdf (last accessed September 2013)

27. Swedish Law (Svensk författningssamling). Hälso- och sjukvårdslag (1982: 763) $2 \S$

28. Williams A. Intergenerational equity: an exploration of the 'fair innings' argument. Health Econ 1997; 6: 117-32; http://dx.doi.org/10.1002/(SICI)1099-1050(199703)6:2<117::AID-HEC256>3.0.CO;2-B

29. Johannesson M, Meltzer D. Some reflections on cost-effectiveness analysis. Health Econ 1998; 7: 1-7; http://dx.doi. org/10.1002/(SICI)1099-1050(199802)7:1<1::AID-HEC327>3.0.CO;2-U

30. National board of health and welfare. Guideline, 2013. Available at www.socialstyrelsen.se (last accessed September 2013) 